\title{
MCP-1/CCR2 signaling-mediated astrocytosis is accelerated in a transgenic mouse model of SOD1-mutated familial ALS
}

\author{
Motoko Kawaguchi-Niida*, Tomoko Yamamoto, Yoichiro Kato, Yuri Inose and Noriyuki Shibata
}

\begin{abstract}
Background: Emerging evidence suggests that innate immunity and increased oxidative stress contribute to pathomechanisms in amyotrophic lateral sclerosis (ALS). The aim of the present study was to verify the involvement of monocyte chemoattractant protein-1 (MCP-1) and its specific CC chemokine receptor 2 (CCR2) in the disease progression of ALS. We here demonstrate the expression state of MCP-1 and CCR2 in lumbar spinal cords of mice overexpressing a transgene for G93A mutant human superoxide dismutase 1 (SOD1) (ALS mice) as a mouse model of ALS as well as the involvement of MCP-1/CCR2-mediated signaling in behavior of cultured astrocytes derived from those mice.

Results: Quantitative polymerase chain reaction analysis revealed that MCP-1 and CCR2 mRNA levels were significantly higher in ALS mice than those in nontransgenic littermates (control mice) at the presymptomatic stage. Immunoblot analysis disclosed a significantly higher CCR2/ $\beta$-actin optical density ratio in the postsymptomatic ALS mouse group than those in the age-matched control mouse group. Immunohistochemically, MCP-1 determinants were mainly localized in motor neurons, while CCR2 determinants were exclusively localized in reactive astrocytes. Primary cultures of astrocytes derived from ALS mice showed a significant increase in proliferation activity under recombinant murine MCP-1 stimuli as compared to those from control mice.
\end{abstract}

Conclusions: Our results provide in vivo and in vitro evidence that MCP-1 stimulates astrocytes via CCR2 to induce astrocytosis in ALS with SOD1 gene mutation. Thus, it is likely that MCP-1/CCR2-mediated sigaling is involved in the disease progression of ALS.

Keywords: Amyotrophic lateral sclerosis, Astrocyte, CCR2, MCP-1, Motor neuron, SOD1

\section{Background}

Amyotrophic lateral sclerosis (ALS) is a late onset neurodegenerative disease characterized by a progressive and selective loss of motor neurons in the motor cortex, brain stem motor nuclei, and spinal cord ventral horns [1]. Patients affected with ALS develop progressive muscle weakness associated with neurogenic amyotrophy, and they will die of respiratory failure within 3-5 years unless undergoing artificial ventilation [2]. Approximately $10 \%$ of the ALS patients are familial. About $20 \%$ of the familial ALS patients are associated with mutations in the gene for superoxide dismutase 1 (SOD1) [1]. Mice

\footnotetext{
* Correspondence: mnkawa@research.twmu.ac.jp

Department of Pathology, Tokyo Women's Medical University, 8-1 Kawadacho, Shinjuku-ku, Tokyo 162-8666, Japan
}

carrying a transgene for the mutant human SOD1 gene demonstrate clinicopathological features resembling human ALS [3]. Thus, mutant human SOD1 transgenic mice have been used in a large number of studies on ALS as an outstanding animal model of ALS.

Although the complete pathomechanism of ALS has not yet been understood, several studies have obtained evidence that inflammatory processes, including increased levels of proinflammatory cytokines and proliferation and activation of glial cells in the main lesions, are involved in the disease progression [4]. Actually, our previous report showed increased levels of activated form of p38 mitogen-activated protein kinase (MAPK) and reduced levels of inhibitor of kappa B-alpha $(\mathrm{I} \kappa \mathrm{B} \alpha)$ in G93A mutant SOD1 transgenic mice as well as a beneficial effect of pioglitazone, an antiinflammatory agent of 
the thiazolidinedione group and an artificial agonist of peroxisome proliferator-activated receptor gamma, on survival of motor neurons and suppression of glial activation through inhibition of p38 MAPK activation and upregulation of IkB $\alpha$ expression [5].

As reviewed by Conductier et al., several investigations have demonstrated implications for monocyte chemoattractant protein-1 (MCP-1), a synonym of CC chemokine ligand 2 (CCL2), in neurological disorders [6]. MCP-1, an $8 \mathrm{kDa}$ secretory protein, is released from certain cells to exert a potent proinflammatory effect on its target cells by binding to the specific receptor CCR2 [7]. MCP-1/CCR2-mediated signaling drives the downstream phosphatidylinositol-3 kinase/Akt and MAPK pathways [8-10]. It is known that MCP-1 induces chemotaxis of macrophages and microglia, leading to pathological microgliosis and inflammatory activation in the lesions [11]. This is supported by a number of studies showing that MCP-1 knockout mice are resistant to stroke and autoimmune encephalomyelitis [12,13].

Recent studies have suggested implications for MCP-1 in ALS. Increased levels of MCP-1 in serum or cerebrospinal fluid of sporadic and familial ALS patients [14-18] or spinal cord tissue samples from mutant SOD1 transgenic mice $[19,20]$ have been reported. On the other hand, it is of interest that CCR2 expression levels on the cell surface of circulating monocytes in sporadic ALS patients were very low [21,22]. However, the role of CCR2 in a mouse model of ALS remains to be determined. To address this issue, we evaluated the expression state of CCR2 as well as MCP-1 in the spinal cord of mutant human SOD1 transgenic mice, by quantitative and morphological approaches using a reverse transcriptionquantitative polymerase chain reaction (RT-qPCR), immunohistochemistry, and immunoblotting techniques. We also evaluated in vitro effects of MCP-1 using primary cultures of astrocytes derived from the transgenic mice and nontransgenic littermates.

\section{Results}

MCP-1 and CCR2 mRNA levels are changed in the spinal cord of ALS mice

Using RT-qPCR techniques, expression levels of MCP-1 and CCR2 mRNA in lumbar spinal cords from $\mathrm{G} 1 \mathrm{H}+/-$ (ALS mice) and SJL (control mice) mice were quantitatively compared between the presymptomatic (9-weeks-old mice), onset (12-weeks-old mice), and postsymptomatic (15-weeksold mice) groups. MCP-1 mRNA analysis revealed clear results (Figure 1a). In all of these stages, MCP-1 mRNA levels were significantly higher in the $\mathrm{G} 1 \mathrm{H}+/-$ groups than those in the age-matched SJL groups and agedependently increased in the $\mathrm{G} 1 \mathrm{H}+/$ - groups but not the SJL groups. On the other hand, CCR2 mRNA analysis revealed complicated results (Figure 1b). CCR2 mRNA
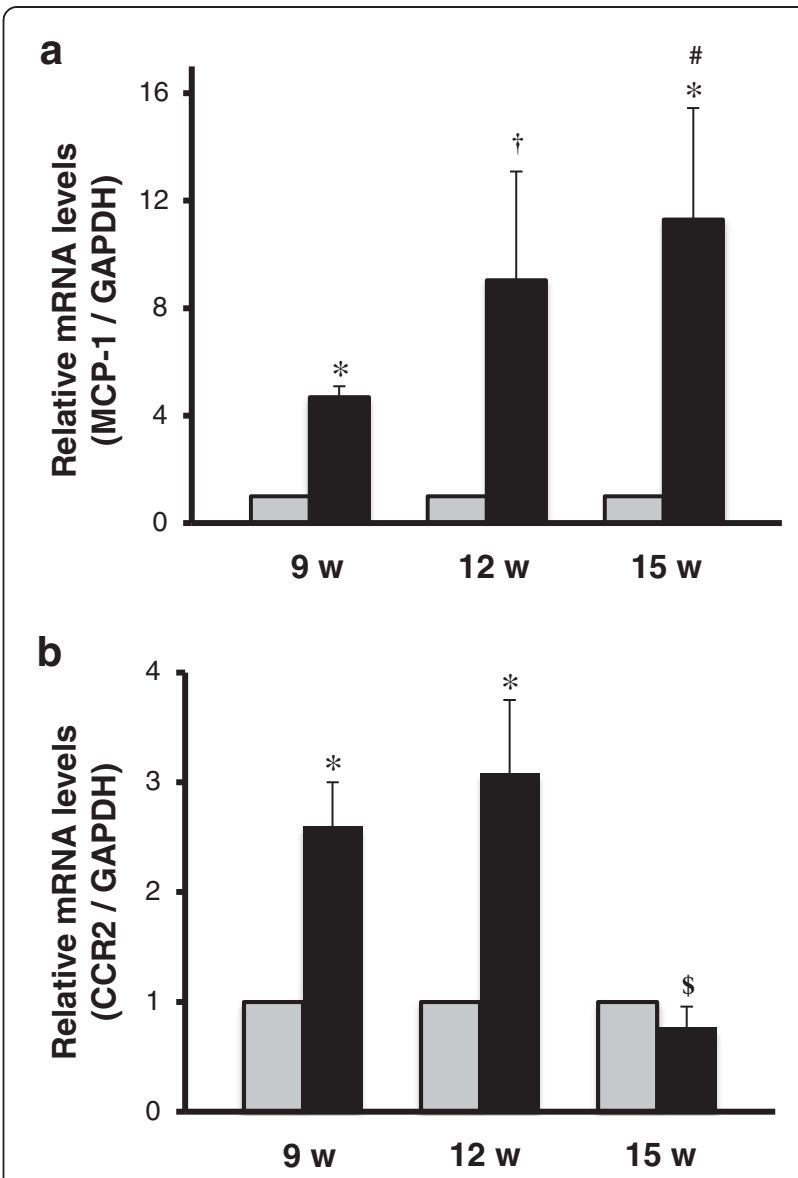

Figure 1 RT-qPCR analysis for MCP-1 and CCR2 mRNA in the spinal cord of mice. MCP-1 (a) and CCR2 (b) mRNA levels normalized with GAPDH mRNA levels are compared between SJL (gray columns) and $\mathrm{G} 1 \mathrm{H}+/$ - (black columns) mice sacrificed at presymptomatic (9 w), onset (12 w), and postsymptomatic (15 w) stages ( $n=6$ in each group). Two-way ANOVA provides $P<0.05$. Posthoc Bonferroni correction provides ${ }^{\#} \mathrm{P}<0.05$ and ${ }^{\$} \mathrm{P}<0.01$ as compared to the presymptomatic and onset $\mathrm{G} 1 \mathrm{H}+/-$ groups and ${ }^{*} \mathrm{P}<0.01$ and ${ }^{\dagger} \mathrm{P}<0.001$ as compared to the age-matched $S J L$ groups.

levels were significantly higher in the presymptomatic and onset $\mathrm{G} 1 \mathrm{H}+/$ - groups than those in the age-matched SJL groups, whereas there was no significant difference in the levels between the postsymptomatic $\mathrm{G} 1 \mathrm{H}+/$ - group and the age-dependent SJL group. In $\mathrm{G} 1 \mathrm{H}+/-$ mice, CCR2 mRNA levels tended to be higher in the onset group than that in the presymptomatic group, and were significantly lower in the postsymptomatic group than in the other groups. By contrast, SJL mice showed constant CCR2 mRNA levels among the three stage groups.

\section{MCP-1 protein is mainly expressed in spinal cord motor neurons of ALS mice}

MCP-1 immunohistochemistry made a striking contrast between $\mathrm{G} 1 \mathrm{H}+/$ - and SJL mice (Figure 2). While MCP-1 immunoreactivity was distinct in pre- and 


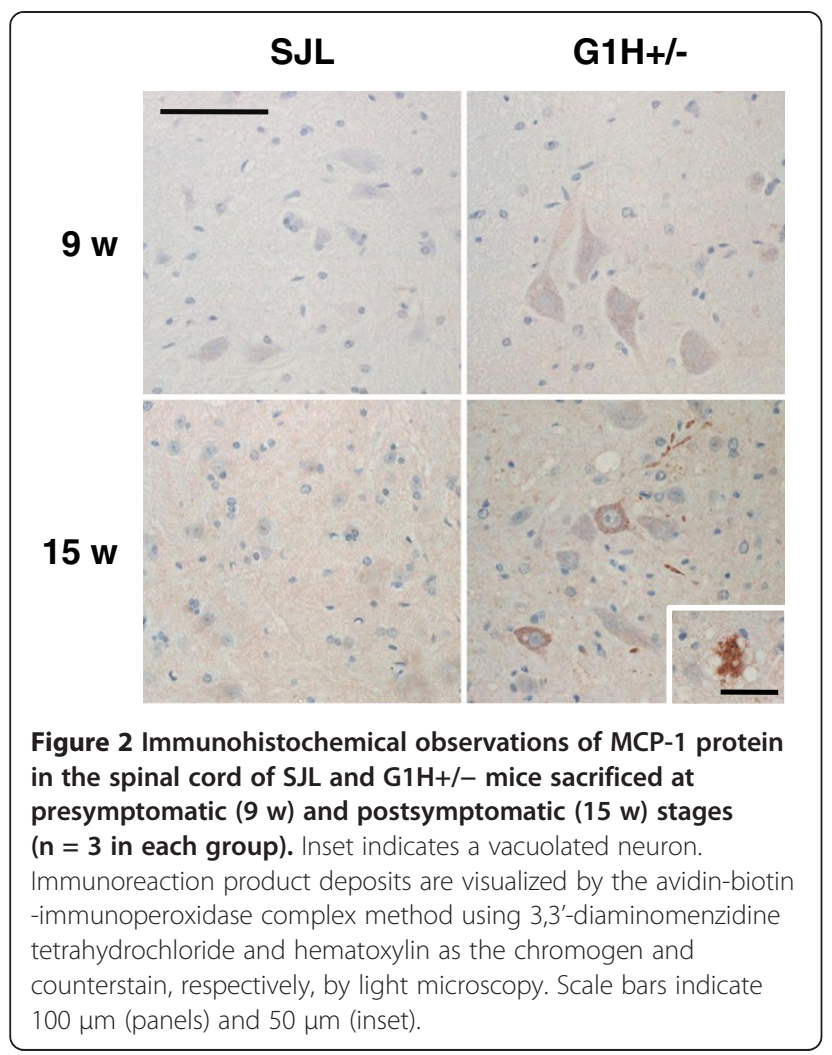

postsymptomatic $\mathrm{G} 1 \mathrm{H}+/$ - mice, it was only very weak or not at all in the age-matched SJL mice. In $\mathrm{G} 1 \mathrm{H}+/-$ mice, immunoreactivity was mainly detectable in the cytoplasm of motor neurons, was more intense in the postsymptomatic group, and was prominent in vacuolated neurons, in particular, but was very weak in glial cells.

\section{CCR2 protein is mainly expressed in spinal cord reactive astrocytes of ALS mice}

CCR2 immunoreactivity also showed distinct alterations between SJL and G1H+/- mice (Figure 3a). The immunoreactivity was only very weak in young to old SJL mice and presymptomatic $\mathrm{G} 1 \mathrm{H}+/$ - mice. By contrast, it was highly intense in onset and postsymptomatic $\mathrm{G} 1 \mathrm{H}$ $+/$ - mice, and was particularly prominent in glial cells, but was undetectable in neurons. To identify CCR2immunoreactive cells, we performed double-labeled immunofluorescence staining of sections from $\mathrm{G} 1 \mathrm{H}$ $+/$ - mice at onset stage. CCR2 immunoreactivity was detected in almost all GFAP-immunoreactive astrocytes (Figure 4d-f; g-i), whereas it was detected in only a few NeuN-immunoreactive neurons (Figure 4a-c) and Iba-1 or CD11b-immunoreactive microglia (Figure 4j-l; $\mathrm{m}-\mathrm{o})$. There was no significant difference in staining patterns between the two different anti-CCR2 antibodies. These results were confirmed by quantitative image analysis; the great majority of CCR2-immunoreactive cells in spinal cord ventral horns were astrocytes but not neurons or microglia (Figure 5).

\section{CCR2 protein levels are increased in the spinal cord of ALS mice}

Expression levels of CCR2 protein in lumbar spinal cords were quantitatively compared between the postsymptomatic SJL and $\mathrm{G} 1 \mathrm{H}+/$ - groups. Immunoblot analysis disclosed CCR2-immunoreactive signals, prominent in the $\mathrm{G} 1 \mathrm{H}+/$ - group, at a mobility of $42 \mathrm{kDa}$ (Figure 3b). Densitometric analysis revealed that immunoreactive signals for CCR2 normalized with those for $\beta$-actin were significantly higher in the $\mathrm{G} 1 \mathrm{H}+/$ - group than in the age-matched SJL group (Figure 3c).

\section{rmMCP-1 induces proliferation of cultured astrocytes derived from ALS mice via CCR2}

Using primary cultures, we compared effects of MCP-1 on the proliferative activity of primary astrocytes derived from SJL and $\mathrm{G} 1 \mathrm{H}+/-$ mice, as determined by a CCK-8 kit. In the absence of rmMCP-1, the basal levels of proliferation activity of astrocytes were significantly increased in the $\mathrm{G} 1 \mathrm{H}+/$ - group as compared to the SJL group. In the presence of rmMCP-1, the levels exhibited a dosedependent increase in the $\mathrm{G} 1 \mathrm{H}+/$ - groups but not the SJL groups (Figure 6a). Phase-contrast images verified an increased density of astrocytes derived from $\mathrm{G} 1 \mathrm{H}+/-$ mice as compared to those from SJL mice (Figure 6b). CCR2 immunoreactivity was intense and localized in the cytoplasm of astrocytes derived from $\mathrm{G} 1 \mathrm{H}+/$ - mice, whereas it was only weak in astrocytes derived from SJL mice (Figure 6c). To determine whether the MCP-1 -driven proliferation of astrocytes derived from $\mathrm{G} 1 \mathrm{H}+/-$ mice may be mediated by the specific receptor CCR2 stimulation, we evaluated the influence of the CCR2 antagonist on the proliferation activity. As a consequence, the levels were significantly reduced in the antagonisttreated $\mathrm{G} 1 \mathrm{H}+/$ - groups as compared to the rmMCP-1 concentration-matched, antagonist-untreated $\mathrm{G} 1 \mathrm{H}+/-$ groups (Figure 6d).

\section{Discussion}

Morphological and quantitative evaluations for MCP-1 in SOD1-mutated mice

It is known that MCP-1 is upregulated by oxidative stress and inflammatory stimuli associated with several pathological conditions including inflammatory and autoimmune diseases and injuries [23,24]. Expression patterns of MCP-1 in the central nervous system (CNS) of postnatal mammalians have been well described. Under physiological conditions, MCP-1 is constitutively expressed in various types of cells, such as neurons, astrocytes, microglia, and endothelial cells at a minimal level. By contrast, it is highly induced in these cells or 


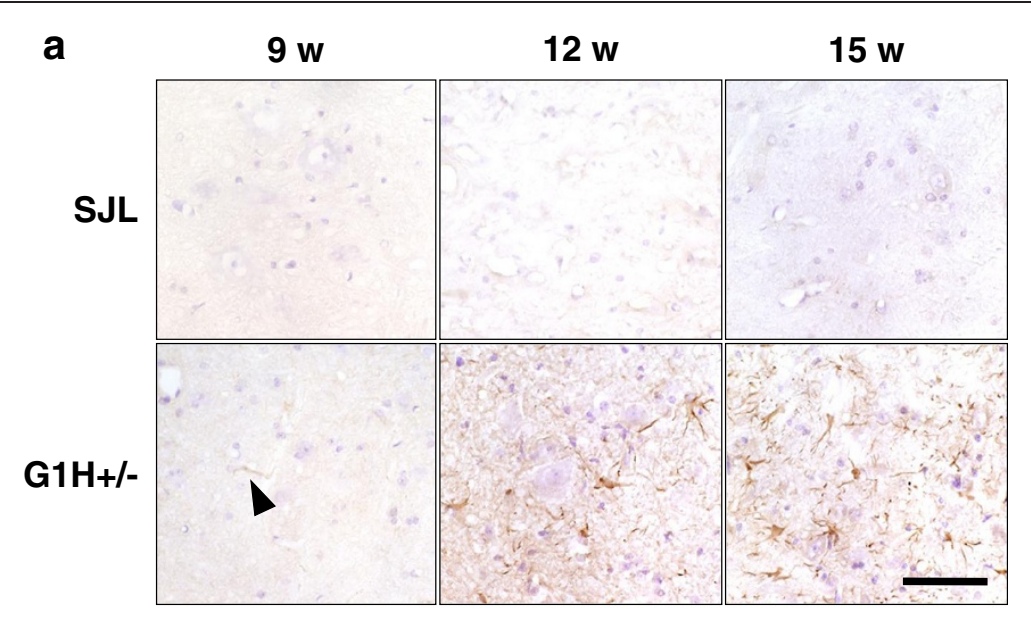

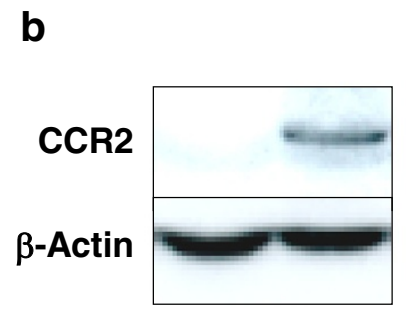

SJL $\mathrm{G} 1 \mathrm{H}+/-$

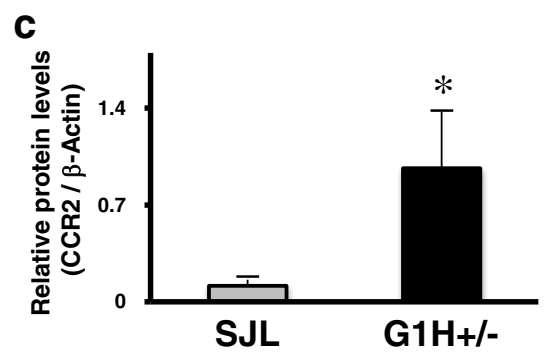

Figure 3 Immunohistochemical (a), immunoblot (b) and densitometric (c) analyses for CCR2 protein in the spinal cord of SJL and G1H +/- mice sacrificed at presymptomatic (9 w), onset (12 w) and postsymptopatic (15 w) stages. Immunoreaction product deposits are visualized by the avidin-biotin-immunoperoxidase complex method using 3,3'-diaminomenzidine tetrahydrochloride and hematoxylin as the chromogen and counterstain, respectively, by light microscopy. Scale bar indicates $100 \mu \mathrm{m}$ (a). Electrophoretic mobility (b) and optical density (c) are compared between the postsymptomatic SJL and $\mathrm{G} 1 \mathrm{H}+/-$ groups ( $\mathrm{n}=5$ in each group). Two-way ANOVA provides $\mathrm{P}<0.05$. Posthoc Bonferroni correction provides * $\mathrm{P}<0.05$ as compared to the SJL group.

peripheral blood-derived monocytes, T cells, or natural killer cells under pathological conditions such as traumatic injury, excitotoxicity, ischemia, inflammation, and neurodegeneration [25-31].

As reviewed by McCombe and Henderson, emerging evidence suggests the involvement of proinflammatory mechanisms in ALS. Recent studies have demonstrated increased expression levels of proinflammatory cytokines and chemokines in activated microglia and reactive astrocytes in human ALS and its transgenic mouse models $[32,33]$. Several studies indicated increased expression levels of MCP-1 in the spinal cord of sporadic ALS patients and SOD1-mutated mice [20]. Other investigators demonstrated the correlation between the cerebrospinal fluid MCP-1 levels and the disease progression and severity of ALS [33,34].

In the present study, immunohistochemical analysis revealed that MCP-1 determinants were mainly localized in the cytoplasm of motor neurons in the spinal cord of G93A mutant SOD1-overexpressing mice in presymptomatic, onset, and postsymptomatic stages, and were, in particular, more intense in vacuolated neurons, than those in age-matched control mice. RT-qPCR analysis of MCP-1 mRNA disclosed agerelated increases in G93A mice but not SJL mice, and significant increases in young to old G93A mice relative to the age-matched SJL mice. These observations are consistent with basic cell biological studies indicating the production of MCP-1 in developing human neurons and the NT2N human neuronal cell line $[35,36]$. Consistent with our findings, Henkel et al. reported increased levels of MCP-1 mRNA and protein in motor neurons as well as reactive glial cells in all stages of SOD1-mutated transgenic mouse models of ALS [20]. Another study demonstrated increased expression of MCP-1 in G93A mutant SOD1-expressing microglia [37,38]. These observations indicate that MCP-1 could be produced by motor neurons and glial cells in the spinal cord of SOD1-mutated ALS mice. However, it should be considered with the caveat that the discrepancy of staining intensity of MCP-1 in glial cells between the present and previous studies may result from differences in the methodologies used. 

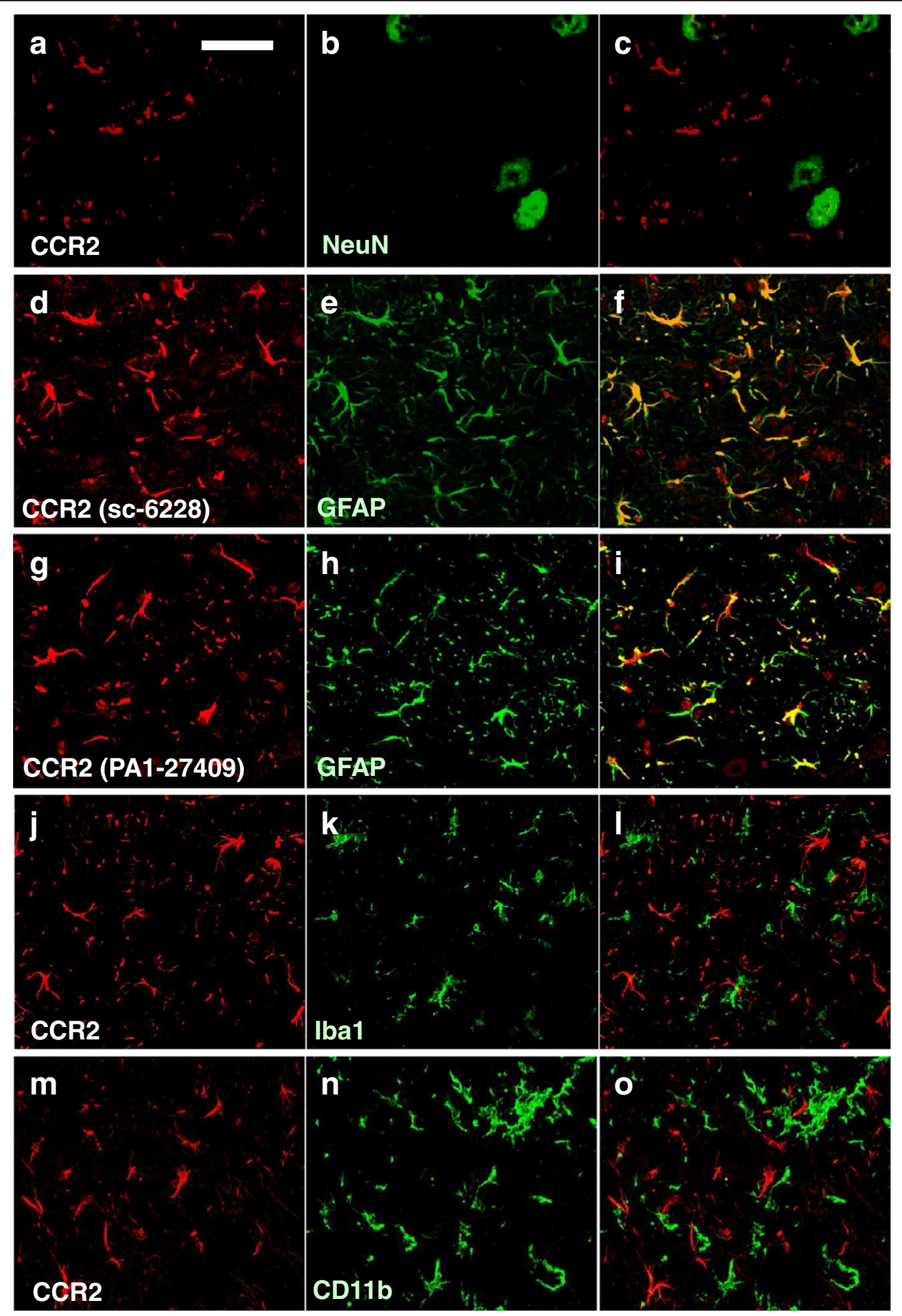

Figure 4 Immunohistochemical observations of CCR2 protein in spinal cord ventral horns from $\mathrm{G} 1 \mathrm{H}+/-$ mice sacrified at onset stage (12 w). Localization of CCR2 immunoreactivity is verified by comparison with that of immunoreactivities for NeuN-immunoreactive (b) neurons, GFAP-immunoreactive $(\mathbf{e}, \mathbf{h})$ astrocytes, and Iba1-immunoreactive $(\mathbf{k})$ and CD11b-immunoreactive $(\mathbf{n})$ microglia. CCR2 immunoreactivity is detected with the two different antibodies sc-6228 (a, $\mathbf{d}, \mathbf{j}, \mathbf{m})$ and PA1-27409 (g), respectively. Panels $(\mathbf{c}, \mathbf{f}, \mathbf{i}, \mathbf{l}, \mathbf{o})$ indicate merged images in two other panels of each line. Immunoreactive signals are detected by the double-labeled immunofluorescence method using secondary antibodies conjugated with Cy3 (red) or FITC (green). Scale bar indicates $50 \mu \mathrm{m}$ (a-o). 


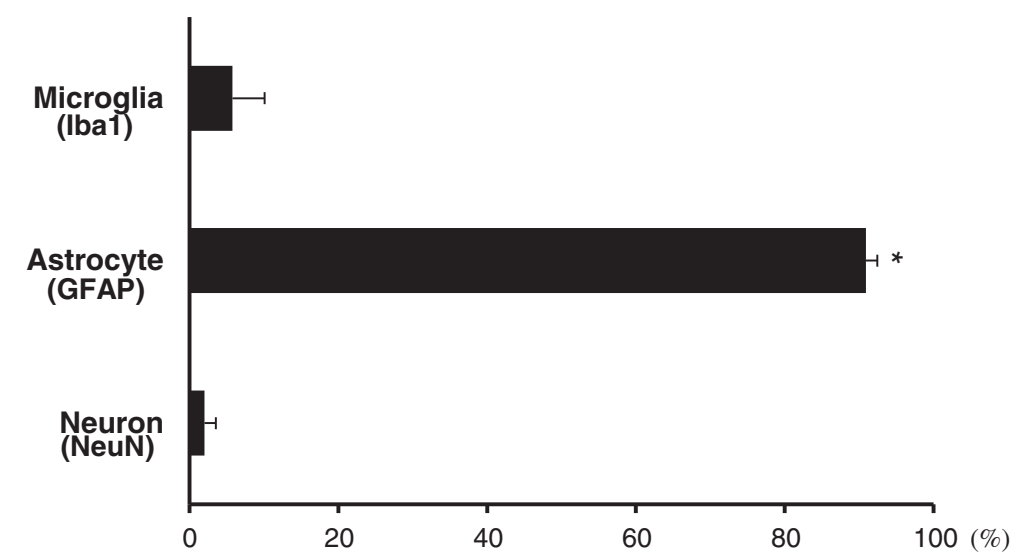

Figure 5 The percentage of CCR2-immunoreactive cells in neurons, astrocytes and microglia. Data obtained by the double-labeled immunofluorescence method are compared by two-way ANOVA $(P<0.01)$ and posthoc Bonferroni correction ${ }^{*} P<0.01$ as compared to the neuronal and microglial groups).

\section{Morphological and quantitative evaluations for CCR2 in SOD1-mutated mice}

It is known that CCR2 acts as a membrane-bound receptor for the specific ligand MCP-1. CCR2 expression is regulated at a low level under physiological conditions [39], whereas it is upregulated by inflammatory stimuli [40]. In several tissues other than the CNS, CCR2 is constitutively expressed in monocytes and macrophages on their cell surface. In the CNS, it has been shown that CCR2 is expressed in microglia and is upregulated under pathological conditions such as multiple sclerosis, Alzheimer's disease, and traumatic brain injury $[30,41,42]$. In the present study, the doublelabeled immunofluorescence staining method revealed that CCR2 immunoreactivity was intense and exclusively localized in reactive astrocytes in the spinal cord of G93A mice at onset and postsymptomatic stages but not SJL mice at any stage. Several studies have provided evidence that astrocytes express CCR2 as the following: (1) MCP-1 and CCR2 are colocalized in astrocytes but not microglia in rat models of experimental autoimmune encephalomyelitis [43]; (2) MCP-1-driven astrocytic activation is associated with CCR2 induction mediated through activation of Akt and NF-kB [44]; (3) primary cultures derived from human and simian astrocytes express CCR2 mRNA and upregulate CCR2 by stimulation of TNF $\alpha$ and IFNY [40]; (4) cultured human astrocytes express CCR2 mRNA and protein and perform chemotaxis and calcium influx in response to MCP-1 stimuli [45]. These observations support our data and suggest that CCR2-expressing astrocytes survive and demonstrate astrocytosis occurring in the advanced stage of a mutant SOD1 transgenic mouse of ALS.
Under physiological conditions, astrocytes behave as architectural components as well as participate in neuroprotective mechanisms, forming morphological and functional bases of the CNS. On the other hand, astrocytes are involved in several pathological conditions by exerting diverse effects on lesional microenvironments [46]. In particular, astrocytes are implicated in the pathomechanisms of neurological disorders, including Alzheimer's disease [47], Parkinson's disease [48], ALS [49,50], multiple sclerosis [51], and cerebral ischemia [52] via inflammatory responses. Relevantly, recent evidence that selective excision of a mutated SOD1 gene in astrocytes inhibited microglial activation and slowed disease progression suggests that mutant SOD1expressing astrocytes are responsible for non-cell autonomous motor neuron death mediated through inflammatory mechanisms on the basis of crosstalk to microglia [53].

In the present study, we investigated CCR2 mRNA and protein expression levels in the spinal cord of SJL and G93A mice. In SJL mice, both the mRNA and protein levels were constantly low at presymptomatic, onset, and postsymptomatic stages. In G93A mice, CCR2 mRNA levels were increased in presymptomatic and onset stages but decreased in postsymptomatic stage, whereas CCR2 protein levels were significantly higher in the postsymptomatic G93A group than the age-matched SJL group. The discrepancy in expression levels between CCR2 mRNA and protein in postsymptomatic G93A mice may reflect certain mechanisms based on SOD1 mutation. It has been shown that over 30\% of genes exhibit significantly divergent patterns of mRNA and protein levels in Streptomyces coelicolor and that the 


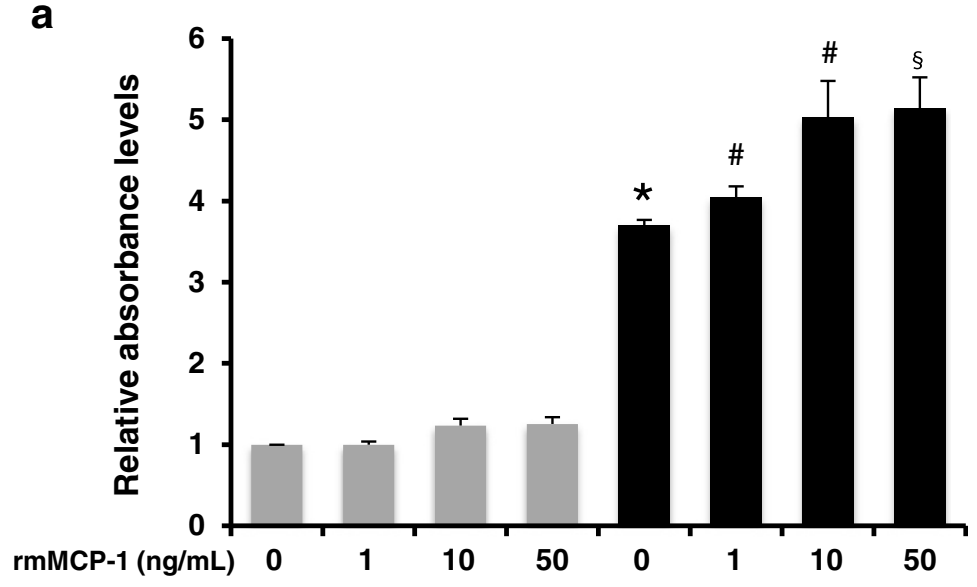

b

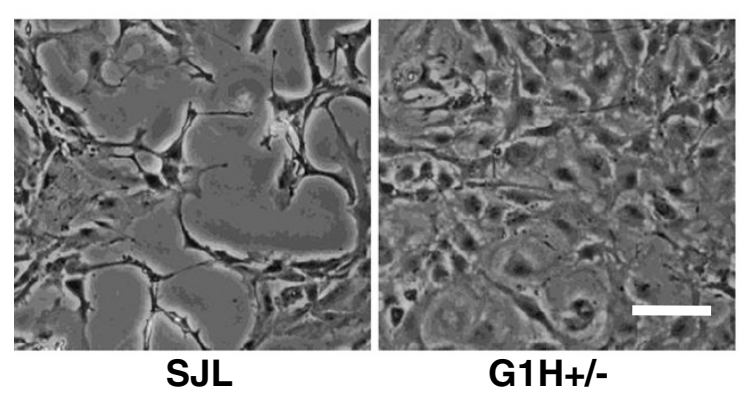

C

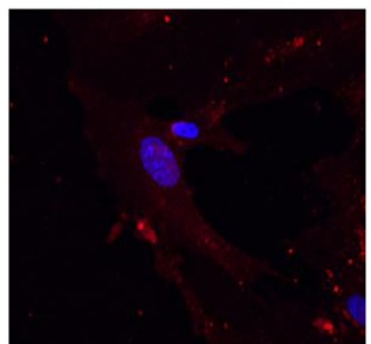

SJL

d
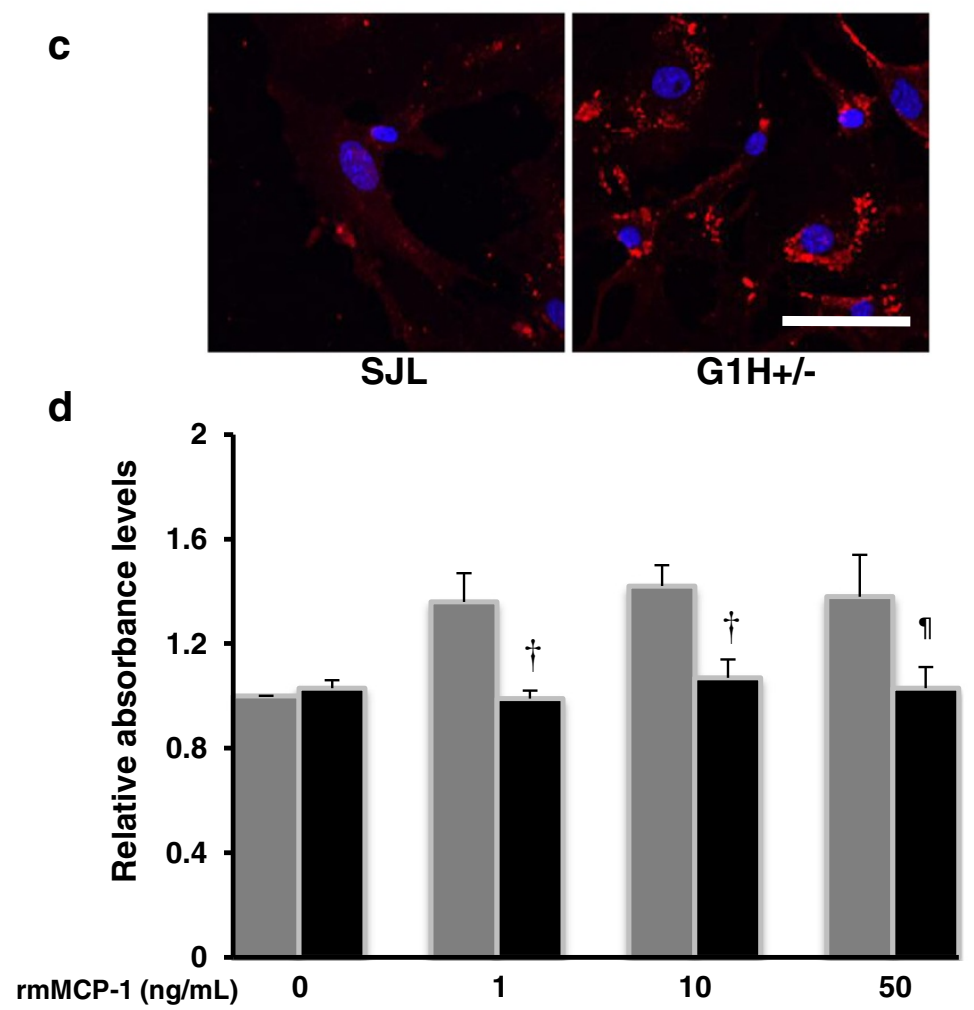

G1H+/-

Figure 6 (See legend on next page.) 
(See figure on previous page.)

Figure 6 Effects of MCP-1 on proliferation activity of astrocytes derived from SJL and G1H+/- mice. Cultured astrocytes derived from SJL (gray columns) and $\mathrm{G} 1 \mathrm{H}+/-$ (black columns) mice are stimulated with recombinant murine MCP-1 (rmMCP-1) at concentrations of $0,1,10$ and 50 $\mathrm{ng} / \mathrm{mL}$ for $48 \mathrm{~h}$, and the proliferation activity determined by a CCK8 kit is compared (a). The $\mathrm{G} 1 \mathrm{H}+/$ - astrocytes are also stimulated with $10 \mathrm{ng} /$ $\mathrm{mL}$ rmMCP-1 in the presence (black columns) or absence (gray columns) of treatment with $10 \mu \mathrm{M} \mathrm{CCR2}$ antagonist, and the proliferation activity is compared (d). Two-way ANOVA provides $\mathrm{P}<0.05(\mathbf{a}, \mathbf{d})$. Posthoc Bonferroni correction provides $* \mathrm{P}<0.001$ as compared to the MCP-1 -unstimulated SJL cell group, ${ }^{\# P}<0.05$ and ${ }^{\S} \mathrm{P}<0.01$ as compared to the MCP-1-unstimulated G1H+/- group, and ${ }^{\text {I }} \mathrm{P}<0.05$ and ${ }^{\dagger} P<0.01$ as compared to the CCR2 antagonist-untreated, rmMCP-1 concentration-matched G1H+/- groups. Morphological changes of cultured astrocytes stimulated with $10 \mathrm{ng} / \mathrm{mL}$ rmMCP-1 are compared between the SJL and $\mathrm{G} 1 \mathrm{H}+/$ - groups by phase-contrast images (b) and CCR2

immunocytochemistry detected by the immunofluorescence method using a secondary antibody conjugated with Cy3 (red) and DAPI (blue) as a nuclear marker (c). Scale bars indicate $50 \mu \mathrm{m}(\mathbf{b}, \mathbf{c})$.

mRNA-protein discordance is attributable to differences in protein translation and degradation rates [54]. The stability of CCR2 protein in G93A mice might be changed by proteasome inhibition, which may occur in the presence of oxidative stress originating in mutant SOD1 toxicity [55]. CCR2 mRNA levels in human monocytes are also downregulated by treatment with bacteria-derived toxins such as lipopolysaccharide [56]. In cultured human monocytes, mRNA expression levels of the major chemokine receptors, CCR2, CCR5, and CXCR4 are upregulated by treatment with reactive oxygen species, including hydrogen peroxide, and are downregulated by treatment with antioxidant reagents such as pyrrolidine dithiocarbamate and $\mathrm{N}$-acetylcysteine, although these treatments do not influence the stability of CCR2 protein on the cell surface [57]. Irradiationtriggered oxidative stress induces CCR2 protein expression associated with the lipid peroxidation product 4-hydroxy-2-nonenal in mouse hippocampi [58]. Moreover, a recent study indicated reduced CCR 2 mRNA levels in circulating monocytes from sporadic ALS patients [22]. These observations suggest that altered redox states in G93A mice contribute to downregulation of CCR2 mRNA and upregulation or stabilization of CCR2 protein, leading to an increased innate immune response to SOD1 mutationrelated oxidativestress.

\section{MCP-1 induces proliferation of astrocytes derived from SOD1-mutated mice}

It is known that neuroinflammation based on activation of astrocytes and microglia diminishes survival of motor neurons to exacerbate disease progression of ALS [4]. Accumulating evidence suggests that astrocytes expressing mutant SOD1 are highly toxic to motor neurons. In particular, recent studies indicated that cultured astrocytes expressing mutant SOD1 demonstrated increased proliferation activity and reduced glutamate transporter-1 expression. The mutant SOD1-expressing astrocytes seems to produce certain soluble factors, which are toxic to motor neurons and activate microglia to induce motor neuron death $[50,59]$. In the present study, the basic and MCP-1 -driven levels of proliferation activity and CCR2 expression were significantly increased in cultured astrocytes derived from G93A mice as compared to those from SJL mice. Moreover, the MCP-1-driven proliferation activity in the G93A astrocytes was suppressed by a CCR2 antagonist. Given the age-related increase in MCP-1 mRNA levels in the spinal cord of G93A mice, it is evident that astrocytes carrying a transgene for mutant SOD1 play a pivotal role in the disease progression via MCP-1/CCR2mediated signaling.

\section{Conclusions}

Taken together, we here showed a significant upregulation of MCP-1 and CCR2 in the spinal cord of G93A mutant human SOD1-overexpressing mice relative to nontransgenic littermates. This upregulation occurred even if in presymptomatic stage and was then enhanced along with aging. While MCP-1 was mainly expressed in motor neurons, CCR2 was mainly expressed in reactive astrocytes. These results provide in vivo evidence that MCP-1, released from the lesional cells including motor neurons, selectively stimulates CCR2-expressing astrocytes in a paracrine manner, leading to cell activation such as proliferation. Our results suggest that astrocytic activation driven by the MCP-1/CCR2 signaling pathway is a newly identified target of ALS therapies. Finally, determining the precise role of the MCP-1/CCR2 signaling pathway in SOD1-mutated human ALS requires further investigations.

\section{Methods}

\section{Animals}

The present study was approved by the Animal Research Ethics Committee of Tokyo Women's Medical University. Mice overexpressing a transgene for G93A mutant human SOD1 [high expresser $\mathrm{G} 1 \mathrm{H}$ line $(\mathrm{G} 1 \mathrm{H}+/-)$ mice] [60] and nontransgenic littermates [background strain of Jackson Laboratory line (SJL) mice] were obtained from Jackson Laboratory (Bar Harbor, ME, USA). We maintained G1H+/mice by mating transgenic males with nontransgenic females. Transgenic offsprings were genotyped by detecting human SOD1 protein in addition to mouse SOD1 protein using immunoblots as described before [5], and nontransgenic littermates were used as negative controls of the genetic background. After birth, $\mathrm{G} 1 \mathrm{H}+/-$ mice 
Table 1 Primer sets for reverse transcription-quantitative polymerase chain reaction

\begin{tabular}{lll}
\hline Gene & Sequence & Amplicon (bp) \\
\hline MCP-1 & F: 5'-GCATCCACGTGTTGGCTCA-3' & 95 \\
& R: 5'-CTCCAGCCTACTCATTGGGATCA-3' & \\
CCR2 & F: 5'-ACAGCTCAGGATTAACAGGGACTTG-3' & 129 \\
& R: 5'-ACCACTTGCATGCACACATGAC-3' & \\
GAPDH & F: 5'-TGTGTCCGTCGTGGATCTGA-3' & 150 \\
& R: 5'-TTGCTGTTGAAGTCGCAGGAG-3' & \\
\hline
\end{tabular}

Abbreviations: $M C P-1$, monocyte chemoattractant protein-1; CCR2, CC chemokine receptor 2; GAPDH, glyceraldehyde 3-phosphate dehydrogenase; $F$, forward; $R$, reverse; $b p$, base pair.

appeared clinically intact at $9 \mathrm{w}$ (presymptomatic stage), began to show clinical symptoms such as weakness and tremor prominent in their hindlimbs at around $12 \mathrm{w}$ (onset stage), developed progressive gait disturbance reminiscent of human ALS (postsymptomatic stage), and died of respiratory failure or an eating disability by 20 w. Both $\mathrm{G} 1 \mathrm{H}+/$ - and SJL mice were divided into the presymptomatic, onset, and postsymptomatic groups, and were sacrificed under anesthesia with ether ethanol at the respective periods (9 $\mathrm{w}, 12 \mathrm{w}$, and $15 \mathrm{w}$ ) to obtain lumbar spinal cords, including the main lesions in the mouse ALS-like disease.

\section{RT-qPCR analysis}

The primer sets used in RT-qPCR are summarized in Table 1. All of them were purchased from Takara. Total RNA was extracted from freshly frozen materials of lumbar spinal cords using the RNeasy Lipid Tissue Mini kit (Qiagen, Valencia, CA, USA), and in turn were used for RT to obtain cDNA using the Prime Script RT-PCR kit (Takara, Tokyo, Japan). qPCR was performed using cDNA derived from $50 \mathrm{ng}$ of total RNA, primer sets at a final concentration of $50 \mathrm{pM}$, and SYBR Premix Ex Taq II (Takara) according to the manufacturer's instructions. Amplification profiles consisted of $95^{\circ} \mathrm{C}$ for $10 \mathrm{sec}$ (initial denaturing), followed by 45 cycles at $95^{\circ} \mathrm{C}$ for $5 \mathrm{sec}$

Table 2 Primary antibodies used for immunohistochemistry

\begin{tabular}{lllll}
\hline Antigen & Species & Dilution & Cat. No. & Source \\
\hline MCP-1 & Rabbit & $1: 100$ & ab7202 & Abcam \\
CCR2 & Goat & $1: 100$ & sc-6228 & SCB \\
CCR2 & Goat & $1: 100$ & PA1-27409 & Thermo \\
NeuN & Mouse & $1: 300$ & MAB377 & Chemicon \\
GFAP & Rabbit & $1: 500$ & z0334 & Dako \\
CD11b & Rat & $1: 50$ & ab8878 & Abcam \\
Iba1 & Rabbit & $1: 200$ & $019-19741$ & Wako \\
\hline
\end{tabular}

Abbreviations: $M C P-1$, monocyte chemoattractant protein-1; CCR2, CC chemokine receptor 2; GFAP, glial fibrillary acidic protein; $I b a 1$, ionized calcium-binding adaptor molecule 1; SCB, Santa Cruz Biotechnology. (denaturing), $55^{\circ} \mathrm{C}$ for $10 \mathrm{sec}$ (annealing) and $72^{\circ} \mathrm{C}$ for $20 \mathrm{sec}$ (extension). At the end of each run, a melting point analysis was performed to validate the specificity of the PCR products. The quality of the PCR products was also confirmed by ethidium bromide-supplemented agarose gel electrophoresis. House-keeping gene for glyceraldehyde dehydrogenase (GAPDH) was used to normalize transcription levels of MCP-1 and CCR2. The normalized data were compared between the different groups ( $\mathrm{n}=6$ in each group).

\section{Immunohistochemical analysis}

The primary antibodies employed in immunohistochemistry are summarized in Table 2. NeuN and glial fibrillary acidic protein (GFAP) were used as markers for neurons and astrocytes, respectively. Both $\mathrm{CD} 11 \mathrm{~b}$ and Iba1 were used as markers for microglia. For immunohistochemistry, mice were perfused with phosphate-buffered saline, $\mathrm{pH} 7.5$ (PBS) followed by $3 \%$ paraformaldehyde in PBS. Spinal cords were subsequently removed and processed for making paraffinembedded materials or optimal cutting temperature compound-embedded frozen materials. Multiple $7-\mu \mathrm{m}$-thick paraffin-embedded sections and 10- $\mu \mathrm{m}$-thick frozen sections were used for immunohistochemical staining. Paraffinembedded sections were deparaffinized, and frozen sections were air-dried. These sections were subsequently rehydrated, quenched for $20 \mathrm{~min}$ in $3 \%$ hydrogen peroxide in PBS, pretreated for $30 \mathrm{~min}$ at room temperature with $3 \%$ bovine serum albumin in PBS, and in turn incubated overnight at $4^{\circ} \mathrm{C}$ with a primary antibody in PBS containing $0.1 \%$ Triton X-100 and 1\% of normal horse serum. Antibody binding was visualized by the avidin-biotin -immunoperoxidase complex $(\mathrm{ABC})$ method using the appropriate Vectastain ABC kit (Vector Laboratories, Burlingame, CA, USA) according to the manufacturer's instructions. 3,3'-Diaminobenzidine tetrahydrochloride was the chromogen, and hematoxylin, the counterstain.

Tissue distribution of MCP-1 and CCR2 was roughly verified by comparison with consecutive sections stained with hematoxylin-eosin (H\&E). Immunohistochemical localization of CCR2 was precisely identified by the double-labeled immunofluorescence method. In brief, sections were incubated simultaneously with the primary antibodies against a target substance and a cell marker followed by the secondary antibodies such as Cy3conjugated donkey anti-goat IgG and fluorescein isothiocyanate (FITC)-conjugated donkey anti-mouse, rat, or rabbit IgG (each diluted 1:200; Jackson Immunoresearch Laboratory, West Grove, PA, USA). DAPI was use as a nuclear stain. Immunoreaction product deposits were observed and recorded with a fluorescence microscope (Nikon ECLIPSE TS100; Nikon, Tokyo, Japan) or a confocal laser microscope (LSM 510 Meta, Carl Zeiss, Jena, Germany). The percentage of CCR2-immunoreactive 
cells in neurons, astrocytes, and microglia in the ventral horns was verified by NIH image J software.

\section{Immunoblot analysis}

Resected fresh mouse spinal cords were stored at $-80^{\circ} \mathrm{C}$ until use. For immunoblotting, frozen spinal cord materials were homogenized in $20 \mathrm{mM}$ Tris-buffered saline, $\mathrm{pH} 8.5$ (TBS), supplemented with $5 \mathrm{mM}$ ethylenediaminetetraacetic acid (EDTA), 10\% glycerol, 1\% Triton X-100, 0.1\% sodium dodecyl sulfate (SDS), $0.5 \%$ sodium deoxycholic acid, $1 \mathrm{mM}$ phenylmethylsulfonylfluoride, and a protease inhibitor cocktail Complete Mini (Roche Diagnostics, Mannheim, Germany) according to the manufacturer's instructions. The homogenate was then centrifuged at 12,500 $\mathrm{g}$ for $15 \mathrm{~min}$ to obtain supernatant containing total protein extracts. Protein concentration was determined by the Bradford method [61]. Total protein extracts were boiled for $10 \mathrm{~min}$ at $100^{\circ} \mathrm{C}$ with an equal volume of Laemli's buffer containing 0.05\% bromophenol blue, and were used for $12 \%$ sodium dodecyl sulfate-polyacrylamide gel electrophoresis. Aliquots of samples (70 $\mu \mathrm{g}$ of protein per lane) were loaded and separated in a gel, were and electroblotted onto a polyvinylidene difluoride (PVDF) membrane (Millipore, Billerica, MA, USA). After transfer, PVDF membranes were pretreated overnight at $4^{\circ} \mathrm{C}$ in $100 \mathrm{mM}$ TBS, containing $0.1 \%$ Tween20 and $5 \%$ skim milk, and then incubated for $1 \mathrm{~h}$ at room temperature with the anti-CCR2 antibody (Santa Cruz) at a dilution of 1:1,000 or mouse anti- $\beta$-actin antibody (SigmaAldrich, St. Louis, MO, USA) at a dilution of 1:2,000. Blots processed with omission of the primary antibodies served as negative reaction controls. Immunoreactive signals were visualized by the chemiluminescence method using the appropriate ECL detection system kit (Amersham, Buckinghamshire, UK), scanned with a Light-Capture Cooled Camera system (ATTO, Tokyo, Japan), and imported onto a personal computer. Optical density was then quantified with NIH Image J software. In each sample, immunoreactive signals for CCR2 were normalized by those for $\beta$-actin, and the CCR $2 / \beta$-actin optical density ratio was compared between the different groups.

\section{Cell culture and proliferation assay}

Astrocytes were grown in primary culture as described previously [62]. Briefly, the cerebral hemispheres of newborn SJL and $\mathrm{G} 1 \mathrm{H}+/$ - mice were removed, the meninges were carefully removed off, and the cerebral tissues were dissociated with trypsin. The dissociated cells were seeded at 1.4 $\times 10^{4}$ viable cells $/ \mathrm{cm}^{2}$ in a plastic culture flask and grown for 2 weeks in Dulbecco's modified Eagle's medium with $20 \% \mathrm{~F}-12$ and $10 \%$ fetal bovine serum at $37^{\circ} \mathrm{C}$ in a $5 \% \mathrm{CO}_{2}$ incubator. Before experiments, immunocytochemistry confirmed that over $95 \%$ of the cells were stained positively for the astrocytic marker GFAP. For proliferation assay, cells were plated on 96-well plates $\left(4 \times 10^{3}\right.$ cells/well $)$ and allowed to adhere for $24 \mathrm{~h}$ at $37^{\circ} \mathrm{C}$. The cultures were then stimulated with recombinant murine MCP-1 (rmMCP-1; Pepro Tech, Rocky Hill, NJ, USA) at concentrations of 0,1 , 10 and $50 \mathrm{ng} / \mathrm{mL}$ for $48 \mathrm{~h}$ in the presence or absence of a CCR2 antagonist (Calbiochem, La Jolla, CA, USA) at a final concentration of $10 \mu \mathrm{M}$, followed by incubation with a Cell Counting Kit-8 (CCK-8; Dojindo Laboratories, Kumamoto, Japan) solution at a final concentration of $10 \mu \mathrm{M}$, and the cells were incubated for $2 \mathrm{~h}$ at $37^{\circ} \mathrm{C}$, according to the manufacturer's instructions. The optical absorbance at $450 \mathrm{~nm}$ for each sample was measured using a microplate reader (Bio-Lad Laboratories, Richmond, CA, USA).

\section{Statistics}

Data were compared between three or more groups by two-way analysis of variance (ANOVA) followed by posthoc Bonferroni correction. Significance was considered in the case of P-value $<0.05$.

\section{Competing interests}

The authors declare that they have no competing interest.

\section{Author's contributions}

MKN performed most experiments. TY, YK and YI carried out in part the morphological and quantitative analyses. NS participated in the study design and coordination, and helped to draft the manuscript. All authors read and approved the final manuscript.

\section{Acknowledgements}

We would like to thank Dr. Y. Takakuwa for valuable suggestions and Mr. Y. Shigematsu for skillful technical assistance.

Received: 23 April 2013 Accepted: 14 May 2013

Published: 4 June 2013

\section{References}

1. Ince PG, Highley JR, Kirby J, Wharton SB, Takahashi H, Strong MJ, Shaw PJ: Molecular pathology and genetic advances in amyotrophic lateral sclerosis: an emerging molecular pathway and the significance of glial pathology. Acta Neuropathol 2011, 122:657-671.

2. Rowland LP, Shneider NA: Amyotrophic lateral sclerosis. N Engl J Med 2001, 344:1688-1700.

3. Gurney ME, Pu H, Chiu AY, Dal Canto MC, Polchow CY, Alexander DD, Caliendo J, Hentati A, Kwon Y, Deng HX: Motor neuron degeneration in mice that express a human $\mathrm{Cu}, \mathrm{Zn}$ superoxide dismutase mutation. Science 1994, 264:1772-1775.

4. McCombe PA, Henderson RD: The Role of immune and inflammatory mechanisms in ALS. Curr Mol Med 2011, 11:246-254.

5. Shibata N, Kawaguchi-Niida M, Yamamoto T, Toi S, Hirano A, Kobayashi M: Effects of the PPARy activator pioglitazone on p38 MAP kinase and IKBa in the spinal cord of a transgenic mouse model of amyotrophic lateral sclerosis. Neuropathology 2008, 28:387-398.

6. Conductier G, Blondeau N, Guyon A, Nahon JL, Rovère C: The role of monocyte chemoattractant protein MCP1/CCL2 in neuroinflammatory diseases. J Neuroimmunol 2010, 224:93-100.

7. Gu L, Tseng SC, Rollins BJ: Monocyte chemoattractant protein-1. Chem Immunol 1999, 72:7-29.

8. Li MQ, Li HP, Meng YH, Wang XQ, Zhu XY, Mei J, Li DJ: Chemokine CCL2 enhances survival and invasiveness of endometrial stromal cells in an autocrine manner by activating Akt and MAPK/Erk1/2 signal pathway. Fertil Steril 2012, 97(4):919-929.

9. Loberg RD, Day LL, Harwood J, Ying C, St John LN, Giles R, Neeley CK, Pienta $\mathrm{KJ}$ : CCL2 is a potent regulator of prostate cancer cell migration and proliferation. Neoplasia 2006, 8:578-586. 
10. Lu Y, Cai Z, Galson DL, Xiao G, Liu Y, George DE, Melhem MF, Yao Z, Zhang $\mathrm{J}$ : Monocyte chemotactic protein-1 (MCP-1) acts as a paracrine and autocrine factor for prostate cancer growth and invasion. Prostate 2006, 66:1311-1318.

11. El Khoury J, Luster AD: Mechanisms of microglia accumulation in Alzheimer's disease: therapeutic implications. Trends Pharmacol Sci 2008, 29:626-632.

12. Huang DR, Wang J, Kivisakk P, Rollins BJ, Ransohoff RM: Absence of monocyte chemoattractant protein 1 in mice leads to decreased local macrophage recruitment and antigen-specific T helper cell type 1 immune response in experimental autoimmune encephalomyelitis. J Exp Med 2001, 193:713-726.

13. Hughes PM, Allegrini PR, Rudin M, Perry VH, Mir AK, Wiessner C: Monocyte chemoattractant protein-1 deficiency is protective in a murine stroke model. J Cereb Blood Flow Metab 2002, 22:308-317.

14. Baron P, Bussini S, Cardin V, Corbo M, Conti G, Galimberti D, Scarpini E, Bresolin N, Wharton S, Shaw PJ, Silani V: Production of monocyte chemoattractant protein-1 in amyotrophic lateral sclerosis. Muscle Nerve 2005, 32:541-544.

15. Gupta PK, Prabhakar S, Sharma S, Anand A: A predictive model for amyotrophic lateral sclerosis (ALS) diagnosis. J Neurol Sci 2012, 312:68-72.

16. Henkel JS, Engelhardt Jl, Siklós L, Simpson EP, Kim SH, Pan T, Goodman JC, Siddique T, Beers DR, Appel SH: Presence of dendritic cells, MCP-1, and activated microglia/macrophages in amyotrophic lateral sclerosis spinal cord tissue. Ann Neurol 2004, 55:221-235.

17. Simpson EP, Henry YK, Henkel JS, Smith RG, Appel SH: Increased lipid peroxidation in sera of ALS patients: a potential biomarker of disease burden. Neurology 2004, 62:1758-1765.

18. Wilms H, Sievers J, Dengler R, Bufler J, Deuschl G, Lucius R: Intrathecal synthesis of monocyte chemoattractant protein-1 (MCP-1) in amyotrophic lateral sclerosis: further evidence for microglial activation in neurodegeneration. J Neuroimmunol 2003, 144:139-142.

19. Beers DR, Zhao W, Liao B, Kano O, Wang J, Huang A, Appel SH, Henkel JS: Neuroinflammation modulates distinct regional and temporal clinical responses in ALS mice. Brain Behav Immun 2011, 25:1025-1035.

20. Henkel JS, Beers DR, Siklós L, Appel SH: The chemokine MCP-1 and the dendritic and myeloid cells it attracts are increased in the mSOD1 mouse model of ALS. Mol Cell Neurosci 2006, 31:427-437.

21. Mantovani S, Garbelli S, Pasini A, Alimonti D, Perotti C, Melazzini M, et al: Immune system alterations in sporadic amyotrophic lateral sclerosis patients suggest an ongoing neuroinflammatory process. J Neuroimmunol 2009, 210:73-79.

22. Zhang R, Gascon R, Miller RG, Gelinas DF, Mass J, Lancero M, Narvaez A, McGrath MS: MCP-1 chemokine receptor CCR2 is decreased on circulating monocytes in sporadic amyotrophic lateral sclerosis (sALS). J Neuroimmunol 2006, 179:87-93.

23. Dawson J, Miltz W, Mir AK, Wiessner C: Targeting monocyte chemoattractant protein-1 signalling in disease. Expert Opin Ther Targets 2003, 7:35-48

24. Roebuck KA, Carpenter LR, Lakshminarayanan V, Page SM, Moy JN, Thomas $L L$ : Stimulus-specific regulation of chemokine expression involves differential activation of the redox-responsive transcription factors AP-1 and NF-KB. J Leukoc Biol 1999, 65:291-298.

25. Allavena P, Bianchi G, Zhou D, van Damme J, Jílek P, Sozzani S, Mantovani $A$ : Induction of natural killer cell migration by monocyte chemotactic protein-1, -2 and -3. Eur J Immunol 1994, 24:3233-3236.

26. Amantea D, Nappi G, Bernardi G, Bagetta G, Corasaniti MT: Post-ischemic brain damage: pathophysiology and role of inflammatory mediators. FEBS J 2009, 276:13-26.

27. Hinojosa AE, Garcia-Bueno B, Leza JC, Madrigal JL: CCL2/MCP-1 modulation of microglial activation and proliferation. J Neuroinflammation 2011, 8:77.

28. Lee EO, Park HJ, Kang JL, Kim HS, Chong YH: Resveratrol reduces glutamate-mediated monocyte chemotactic protein-1 expression via inhibition of extracellular signal-regulated kinase 1/2 pathway in rat hippocampal slice cultures. J Neurochem 2010, 112:1477-1487.

29. Mahad D, Callahan MK, Williams KA, Ubogu EE, Kivisäkk P, Tucky B, et al: Modulating CCR2 and CCL2 at the blood-brain barrier: relevance for multiple sclerosis pathogenesis. Brain 2006, 129:212-223.

30. Semple BD, Bye N, Rancan M, Ziebell JM, Morganti-Kossmann MC: Role of CCL2 (MCP-1) in traumatic brain injury (TBI): evidence from severe TBI patients and CCL2-/- mice. J Cereb Blood Flow Metab 2010, 30:769-782.
31. Tanabe S, Heesen M, Berman MA, Fischer MB, Yoshizawa I, Luo Y, Dorf ME: Murine astrocytes express a functional chemokine receptor. J Neurosci 1997, 17:6522-6528.

32. Kuhle J, Lindberg RL, Regeniter A, Mehling M, Steck AJ, Kappos L, Czaplinski $A$ : Increased levels of inflammatory chemokines in amyotrophic lateral sclerosis. Eur J Neurol 2009, 16:771-774.

33. Philips T, Robberecht W: Neuroinflammation in amyotrophic lateral sclerosis: role of glial activation in motor neuron disease. Lancet Neurol 2011, 10:253-263.

34. Tateishi T, Yamasaki R, Tanaka M, Matsushita T, Kikuchi H, Isobe N, Ohyagi Y, Kira J: CSF chemokine alterations related to the clinical course of amyotrophic lateral sclerosis. J uroimmunol 2010, 222:76-81.

35. Coughlan CM, McManus CM, Sharron M, Gao Z, Murphy D, Jaffer S, et al: Expression of multiple functional chemokine receptors and monocyte chemoattractant protein-1 in human neurons. Neuroscience 2000, 97:591-600

36. Meng SZ, Oka A, Takashima S: Developmental expressison of monocyte chemoattractant protein-1 in the human cerebellum and brainstem. Brain Dev 1999, 21:30-35.

37. Butovsky O, Siddiqui S, Gabriely G, Lanser AJ, Dake B, Murugaiyanf G, et al: Modulating inflammatory monocytes with a unique microRNA gene signature ameliorates murine ALS. J Clin Invest 2012, 122:3063-3087.

38. Sargsyan SA, Blackburn DJ, Barber SC, Monk PN, Shaw PJ: Mutant SOD1 G93A microglia have an inflammatory phenotype and elevated production of MCP-1. NeuroReport 2009, 20:1450-1455.

39. Semple BD, Kossmann T, Morganti-Kossmann MC: Role of chemokines in CNS health and pathology: a focus on the CCL2/CCR2 and CXCL8/CXCR2 networks. J Cereb Blood Flow Metab 2010, 30:459-473.

40. Croitoru-Lamoury J, Guillemin GJ, Boussin FD, Mognetti B, Gigout LI, Chéret A, Vaslin B, Le Grand R, Brew BJ, Dormont D: Expression of chemokines and their receptors in human and simian astrocytes: evidence for a central role of TNFa and IFNy in CXCR4 and CCR5 modulation. Glia 2003, 41:354-370.

41. Hickman SE, El Khoury J: Mechanisms of mononuclear phagocyte recruitment in Alzheimer's disease. CNS Neurol Disord Drug Targets 2010, 9:168-173.

42. Tanuma N, Sakuma H, Sasaki A, Matsumoto Y: Chemokine expression by astrocytes plays a role in microglia/macrophage activation and subsequent neurodegeneration in secondary progressive multiple sclerosis. Acta Neuropathol 2006, 112:195-204.

43. Jee $Y$, Yoon WK, Okura Y, Tanuma N, Matsumoto Y: Upregulation of monocyte chemotactic protein-1 and CC chemokine receptor 2 in the central nervous system is closely associated with relapse of autoimmune encephalomyelitis in Lewis rats. J Neuroimmunol 2002, 128:49-57.

44. Quinones MP, Kalkonde Y, Estrada CA, Jimenez F, Ramirez R, Mahimainathan $L$, et al: Role of astrocytes and chemokine systems in acute TNFalpha induced demyelinating syndrome: CCR2-dependent signals promote astrocyte activation and survival via NF-kappaB and Akt. Mol Cell Neurosci 2008, 37:96-109.

45. Andjelkovic AV, Song L, Dzenko KA, Cong H, Pachter JS: Functional expression of CCR2 by human fetal astrocytes. J Neurosci Res 2002, 70:219-231.

46. Sofroniew MV, Vinters HV: Astrocytes: biology and pathology. Acta Neuropathol 2010, 119:7-35.

47. Xia MQ, Hyman BT: Chemokines/chemokine receptors in the central nervous system and Alzheimer's disease. J Neurovirol 1999, 5:32-41.

48. Rappold PM, Tieu K: Astrocytes and therapeutics for Parkinson's disease. Neurotherapeutics 2010, 7:413-423.

49. Ferraiuolo L, Higginbottom A, Heath PR, Barber S, Greenald D, Kirby J, Shaw PJ: Dysregulation of astrocyte-motoneuron cross-talk in mutant superoxide dismutase 1-related amyotrophic lateral sclerosis. Brain 2011, 134:2627-2641.

50. Papadeas ST, Kraig SE, O'Banion C, Lepore AC, Maragakis NJ: Astrocytes carrying the superoxide dismutase 1 (SOD1G93A) mutation induce wildtype motor neuron degeneration in vivo. Proc Natl Acad Sci USA 2011, 108:17803-17808.

51. van Der Voorn P, Tekstra J, Beelen RH, Tensen CP, Van Der Valk P, De Groot $\mathrm{CJ}$ : Expression of MCP-1 by reactive astrocytes in demyelinating multiple sclerosis lesions. Am J Pathol 1999, 154:45-51.

52. Takano T, Oberheim N, Cotrina ML, Nedergaard M: Astrocytes and ischemic injury. Stroke 2009, 40:S8-12. 
53. Yamanaka K, Chun SJ, Boillee S, Fujimori-Tonou N, Yamashita H, Gutmann DH, Takahashi R, Misawa H, Cleaveland DW: Astrocytes as determinants of disease progression in inherited amyotrophic lateral sclerosis. Nat Neurosci 2008, 11:251-253.

54. Jayapal KP, Philp RJ, Kok YJ, Yap MG, Sherman DH, Griffin TJ, Hu WS: Uncovering genes with divergent mRNA-protein dynamics in Streptomyces coelicolor. PLoS One 2008, 3:e2097.

55. Kabashi E, Durham HD: Failure of protein quality control in amyotrophic lateral sclerosis. Biochim Biophys Acta 2006, 1762:1038-1050.

56. Sica A, Saccani A, Borsatti A, Power CA, Wells TN, Luini W, Polentarutti N, Sozzani S, Mantovani A: Bacterial lipopolysaccharide rapidly inhibits expression of $\mathrm{C}-\mathrm{C}$ chemokine receptors in human monocytes. J Exp Med 1997, 185:969-974

57. Saccani A, Saccani S, Orlando S, Sironi M, Bernasconi S, Ghezzi P, Mantovani A, Sica A: Redox regulation of chemokine receptor expression. Proc Natl Acad Sci USA 2000, 97:2761-2766.

58. Limoli CL, Giedzinski E, Baure J, Rola R, Fike JR: Redox changes induced in hippocampal precursor cells by heavy ion irradiation. Radiat Environ Biophys 2007, 46:167-172.

59. Díaz-Amarilla P, Olivera-Bravo S, Trias E, Cragnolini A, Martínez-Palma L, Cassina P, Beckman J, Barbeito L: Phenotypically aberrant astrocytes that promote motoneuron damage in a model of inherited amyotrophic lateral sclerosis. Proc Natl Acad Sci USA 2011, 108:18126-18131.

60. Gurney ME: Transgenic-mouse model of amyotrophic lateral sclerosis. N Engl J Med 1994, 331:1721-1722.

61. Sapan CV, Lundblad RL, Price NC: Colorimetric protein assay techniques. Biotechnol Appl Biochem 1999, 29:99-108.

62. Kawaguchi M, Shibata N, Horiuchi S, Kobayashi M: Glyoxal inactivates glutamate transporter-1 in cultured rat astrocytes. Neuropathology 2005, 25:27-36.

doi:10.1186/2051-5960-1-21

Cite this article as: Kawaguchi-Niida et al: MCP-1/CCR2 signalingmediated astrocytosis is accelerated in a transgenic mouse model of SOD1-mutated familial ALS. Acta Neuropathologica Communications 2013 $1: 21$

\section{Submit your next manuscript to BioMed Central and take full advantage of:}

- Convenient online submission

- Thorough peer review

- No space constraints or color figure charges

- Immediate publication on acceptance

- Inclusion in PubMed, CAS, Scopus and Google Scholar

- Research which is freely available for redistribution 